\title{
Levels of Some Phytochemicals in Methanol Extract of Coconut Water
} Ajobiewe $\mathrm{HF}^{1,2}$, Ajobiewe $\mathrm{JO}^{1,3}$, Egbe $\mathrm{JO}^{1}$, Ogundeji $\mathrm{AA}^{4}$, Umeji LC

${ }^{1}$ National Open University of Nigeria, Jabi, Abuja, Nigeria

${ }^{2}$ Biological Sciences Department, Bingham University Karu, Nasarawa State,Nigeria

${ }^{3}$ Microbiology Department, National Hospital,Plot 132, Garki, Abuja, F.C.T. Nigeria

${ }^{4}$ United State Department of Defence, Walter Reed Program-Nigeria, US Embassy, Abuja, Nigeria

${ }^{5}$ Defence Reference Laboratory, Asokoro, Abuja, Nigeria

DOI: $10.36347 /$ sjams.2020.v08i06.038

| Received: 01.06.2020 | Accepted: 15.06.2020 | Published: 30.06 .2020

*Corresponding author: Ajobiewe HF

Abstract

The aim of this research is to determine the levels of some phytochemicals in methanol extract of Coconut water. Medicinal plants are the local heritage with global importance. In fact plants used for medications are the basis of many modern pharmaceuticals today. The work thus investigated the methanol based phytochemical extract of Coconut water. The method involved the use of pooled Coconut water obtained from fifty Coconut fruits at different Markets in various locations in Abuja F.C.T. Methanol extraction of Coconut Phytochemicals was the central focus of the technique adopted. The Spearman's Ranked Correlation Coefficient statistics technique was used to test the level of correlation between the visually scored colour intensity of the phytochemicals of interest and their spectrophotometric ally measured absorbance values at $200 \mathrm{~nm}$ to $600 \mathrm{~nm}$. The targeted Phytochemicals were Alkaloids, Glycosides, Saponins, Tannins, Resins, Acidic compounds and Flavonoids. The Result revealed that Alkaloids that were subjectively scored 4+ with light Purple colour intensity had absorbance, OD, of 300nm. Tannins and Resins, scored 3+ each, with Light Blue colour intensity, had absorbance, OD, of 400nm. Glycosides and Saponin each separately scored 2+, with Green colour intensity had absorbance, OD, of $200 \mathrm{~nm}$. While no colours were detected in Flavonoids and Acidic compounds and as such their absorbances could not be evaluated. Their Statistical proportions on Pie Chart were $142.9^{0}, 102.9^{0}, 102.9^{0}$ and $0^{0}$ respectively. Students $t$ test revealed that $t_{\text {cal }} \geq \mathrm{t}_{\text {tab. }}$ At $95 \%$ confidence limits the levels of the phytochemicals extracted from the Coconut water using methanol extract are quite significant $(\mathrm{P}<0.05)$.

Keywords: Levels, Phytochemicals, Tannins, Alkaloids, Flavonoids, Saponins, Absorbance Glycosides.

Copyright @ 2020: This is an open-access article distributed under the terms of the Creative Commons Attribution license which permits unrestricted use, distribution, and reproduction in any medium for non-commercial use (NonCommercial, or CC-BY-NC) provided the original author and source are credited.

\section{INTRODUCTION}

Medicinal plants' Phytochemicals have been the mainstay of traditional herbal medicine amongst rural dwellers worldwide since antiquity to date. The therapeutic use of plants certainly goes back to the Sumerian and the Akkadian civilizations in about the third millennium BC. Hippocrates (ca. 460-377 BC), one of the ancient authors who described medicinal natural products of plant and animal origins, listed approximately 400 different plant species for medicinal purposes. Natural products have been an integral part of the ancient traditional medicine systems, e.g. Chinese, Ayurvedic and Egyptian [1]. Over the years they have assumed a very central stage in modern civilization as natural source of chemotherapy as well as amongst scientist in search for alternative sources of drugs. About 3.4 billion people in the developing world depend on plant-based traditional medicines. This represents about 88 per cent of the world's inhabitants, who rely mainly on traditional medicine for their primary health care [2]. According to the World Health Organization, a medicinal plant is any plant which, in one or more of its organs, contains substances that can be used for therapeutic purposes, or which are precursors for chemo-pharmaceutical semi synthesis. Such a plant will have its parts including leaves, roots, rhizomes, stems, barks, flowers, fruits, grains or seeds, employed in the control or treatment of a disease condition and therefore contains chemical components that are medically active. These non-nutrient plant chemical compounds or bioactive components are often referred to as phytochemicals ('phyto-'from Greek phyto meaning 'plant') or phytoconstituents and are responsible for protecting the plant against microbial infections or infestations by pests [3]. The study of natural products on the other hand is called phytochemistry. Phytochemicals have been isolated and characterized from fruits such as grapes and apples, vegetables such as broccoli and onion, spices such as 
turmeric, beverages such as green tea and red wine, as well as many other sources [4].

The science of application of these indigenous or local medicinal remedies including plants for treatment of diseases is currently called ethno pharmacology but the practice dates back since antiquity. Ethno pharmacology has been the mainstay of traditional medicines the entire world and currently is being integrated into mainstream medicine. Different catalogues including De Materia Medica, Historia Plantarum, and Species Plantarum have been variously published in attempt to provide scientific information on the medicinal uses of plants. The types of plants and methods of application vary from locality to locality with $80 \%$ of rural dwellers relying on them as means of treating various diseases. For example, the use of bearberry (Arctostaphylo suva-ursi) and cranberry juice (Vaccinium macrocarpon) to treat urinary tract infections is reported in different manuals of phytotherapy, while species such as lemon balm (Melissa officinalis), garlic (Allium sativum) and tee tree (Melaleuca alternifolia) are described as broadspectrum antimicrobial agents [5]. A single plant may be used for the treatment of various disease conditions depending on the community. Several ailments including fever, asthma, constipation, esophageal cancer and hypertension have been treated with traditional medicinal plants [6].

The plants are applied in different forms such as poultices, concoctions of different plant mixtures, infusions as teas or tinctures or as component mixtures in porridges and soups administered in different ways including oral, nasal (smoking, snoffing or steaming), topical (lotions, oils or creams), bathing or rectal (enemas) [7]. Different plant parts and components (roots, leaves, stem barks, flowers or their combinations, essential oils) have been employed in the treatment of infectious pathologies in the respiratory system, urinary tract, gastrointestinal and biliary systems, as well as on the skin [8].

Medicinal plants are increasingly gaining acceptance even among the literates in urban settlements, probably due to the increasing inefficacy of many modern drugs used for the control of many infections such as typhoid fever, gonorrhoea, and tuberculosis as well as increase in resistance by several bacteria to various antibiotics and the increasing cost of prescription drugs, for the maintenance of personal health [9].

Unfortunately, rapid explosion in human population has made it almost impossible for modern health facilities to meet health demands all over the world, thus putting more demands on the use of natural herbal health remedies. Current problems associated with the use of antibiotics, increased prevalence of multiple-drug resistant (MDR) strains of a number of pathogenic bacteria such as methicillin resistant
Staphylococcus aureus, Helicobacter pylori, and Multi Drug Resistant (MDR) Klebsiella pneumonia has revived the interest in plants with antimicrobial properties [10]. In addition, the increase in cases of opportunistic infections and the advent of Acquired Immune Deficiency Syndrome (AIDS) patients and individuals on immunosuppressive chemotherapy, toxicity of many antifungal and antiviral drugs has imposed pressure on the scientific community and pharmaceutical companies to search alternative and novel drug sources [11].

Classes of phytochemicals include A. Alkaloids: These are the largest group of secondary chemical constituents made largely of ammonia compounds comprising basically of nitrogen bases synthesized from amino acid building blocks with various radicals replacing one or more of the hydrogen atoms in the peptide ring, most containing oxygen. The compounds have basic properties and are alkaline in reaction, turning red litmus paper blue. In fact, one or more nitrogen atoms that are present in an alkaloid, typically as $1^{\circ}, 2^{\circ}$ or $3^{\circ}$ amines, contribute to the basicity of the alkaloid. The degree of basicity varies considerably, depending on the structure of the molecule, and presence and location of the functional groups [1]. They react with acids to form crystalline salts without the production of water. Majority of alkaloids exist in solid such as atropine, some as liquids containing carbon, hydrogen, and nitrogen [12]. Most alkaloids are readily soluble in alcohol and though they are sparingly soluble in water, their salts of are usually soluble. The solutions of alkaloids are intensely bitter. These nitrogenous compounds function in the defence of plants against herbivores and pathogens, and are widely exploited as pharmaceuticals, stimulants, narcotics, and poisons due to their potent biological activities. In nature, the alkaloids exist in large proportions in the seeds and roots of plants and often in combination with vegetable acids. Alkaloids have pharmacological applications as anesthetics and CNS stimulants [13]. More than 12,000-alkaloids are known to exist in about $20 \%$ of plant species and only few have been exploited for medicinal purposes. The name alkaloid ends with the suffix -ine and plant-derived alkaloids in clinical use include the analgesics morphine and codeine, the muscle relaxant $(+)$-tubocurarine, the antibiotics sanguinafine and berberine, the anticancer agent vinblastine, the antiarrythmic ajmaline, the pupil dilator atropine, and the sedative scopolamine. Other important alkaloids of plant origin include the addictive stimulants caffeine, nicotine, codeine, atropine, morphine, ergotamine, cocaine, nicotine and ephedrine. Amino acids act as precursors for biosynthesis of alkaloids with ornithine and lysine commonly used as starting materials [14]. Another phytochemical, B. Glycosides in general, are defined as the condensation products of sugars (including polysaccharides) with a host of different varieties of organic hydroxy (occasionally thiol) compounds (invariably 
monohydrate in character), in such a manner that the hemiacetal entity of the carbohydrate must essentially take part in the condensation. Glycosides are colorless, crystalline carbon, hydrogen and oxygen-containing (some contain nitrogen and sulfur) water-soluble phytoconstituents, found in the cell sap. Chemically, glycosides contain a carbohydrate (glucose) and a noncarbohydrate part (aglycone or genin) [12]. Alcohol, glycerol or phenol represents aglycones. Glycosides are neutral in reaction and can be readily hydrolyzed into its components with ferments or mineral acids [12].

Glycosides are classified on the basis of type of sugar component, chemical nature of aglycone or pharmacological action. The rather older or trivial names of glycosides usually has a suffix 'in' and the names essentially included the source of the glycoside, for instance strophanthidin from Strophanthus, digitoxin from Digitalis, barbaloin from Aloes, salicin from Salix, cantharidin from Cantharides, and prunasin from Prunus. However, the systematic names are invariably coined by replacing the "ose" suffix of the parent sugar with "oside" [15]. These groups of drugs are usually administered in order to promote appetite and aid digestion. Glycosides are purely bitter principles that are commonly found in plants of the Genitiaceae family and though they are chemically unrelated but possess the common property of an intensely bitter taste. The bitters act on gustatory nerves, which results in increased flow of saliva and gastric juices. Chemically, the bitter principles contain the lactone group that may be diterpene lactones (e.g. andrographolide) or triterpenoids (e.g. amarogentin). Some of the bitter principles are either used as astringents due to the presence of tannic acid, as antiprotozoan, or to reduce thyroxine and metabolism. Examples include cardiac glycosides (acts on the heart), anthracene glycosides (purgative, and for treatment of skin diseases), chalcone glycoside (anticancer), amarogentin, gentiopicrin, andrographolide, ailanthone and polygalin [15]. Sarker \& Nahar, [1] reported that extracts of plants that contain cyanogenic glycosides are used as flavouring agents in many pharmaceutical preparations. Amygdalin has been used in the treatment of cancer (HCN liberated in stomach kills malignant cells), and also as a cough suppressant in various preparations. Excessive ingestion of cyanogenic glycosides can be fatal. Some foodstuffs containing cyanogenic glycosides can cause poisoning (severe gastric irritations and damage) if not properly handled [1]. To test for O-glycosides, the plant samples are boiled with $\mathrm{HCl} / \mathrm{H}_{2} \mathrm{O}$ to hydrolyse the anthraquinone glycosides to respective aglycones, and an aqueous base, e.g. $\mathrm{NaOH}$ or $\mathrm{NH}_{4} \mathrm{OH}$ solution, is added to it. For C-glycosides, the plant samples are hydrolysed using $\mathrm{FeCl}_{3} / \mathrm{HCl}$, and an aqueous base, e.g. $\mathrm{NaOH}$ or $\mathrm{NH}_{4} \mathrm{OH}$ solution is added to it. In both cases a pink or violet colour in the base layer after addition of the aqueous base indicates the presence of glycosides in the plant sample [15]. C. Flavonoids are important group of polyphenols widely distributed among the plant flora. Structurally, they are made of more than one benzene ring in its structure (a range of $\mathrm{C} 15$ aromatic compounds) and numerous reports support their use as antioxidants or free radical scavengers [15]. The compounds are derived from parent compounds known as flavans. Over four thousand flavonoids are known to exist and some of them are pigments in higher plants. Quercetin, kaempferol and quercitrin are common flavonoids present in nearly $70 \%$ of plants. Other group of flavonoids include flavones, dihydroflavons, flavans, flavonols, anthocyanidins, proanthocyanidins, calchones and catechin and leucoanthocyanidins [15]. Phenolics, phenols or polyphenolic (or polyphenol extracts) are chemical components that occur ubiquitously as natural colour pigments responsible for the colour of fruits of plants. Phenolics in plants are mostly synthesized from phenylalanine via the action of phenylalanine ammonia lyase (PAL). They are very important to plants and have multiple functions. The most important role may be in plant defense against pathogens and herbivore predators, and thus are applied in the control of human pathogenic infections [16]. They are classified into:- Phenolic acids, Flavonoid polyphenolics (flavonones, flavones, xanthones and catechins). Non-flavonoid polyphenolies Caffeic acid is regarded as the most common of phenolic compounds distributed in the plant flora followed by chlorogenic acid known to cause allergic dermatitis among humans [15]. Phenolics essentially represent a host of natural antioxidants, used as nutraceuticals, and found in apples, green-tea, and red-wine for their enormous ability to combat cancer and are also thought to prevent heart ailments to an appreciable degree and sometimes are anti-inflammatory agents. Other examples include flavones, rutin, naringin, hesperidin and chlorogenic [15].

E. Saponins: The term saponin is derived from Saponaria vaccaria (Quillaja saponaria), a plant, which abounds in saponins and was once used as soap. Saponins therefore possess 'soaplike' behaviour in water, i.e. they produce foam. On hydrolysis, an aglycone is produced, which is called sapogenin. There are two types of sapogenin: steroidal and triterpenoidal. Usually, the sugar is attached at C-3 in saponins, because in most sapogenins there is a hydroxyl group at C-3. Quillaja saponaria is known to contain toxic glycosides quillajic acid and the sapogenin senegin. Quillajic acid is strenutatory and senegin is toxic [15]. Senegin is also present in Polygala senega. Saponins are regarded as high molecular weight compounds in which, a sugar molecule is combined with triterpene or steroid aglycone. There are two major groups of saponins and these include: steroid saponins and triterpene saponins. Saponins are soluble in water and insoluble in ether, and like glycosides on hydrolysis, they give aglycones. Saponins are extremely poisonous, as they cause haemolysis of blood and are known to cause cattle poisoning [15]. They possess a bitter and acrid taste, besides causing irritation to mucous 
membranes. They are mostly amorphous in nature, soluble in alcohol and water, but insoluble in non-polar organic solvents like benzene and n-hexane [15].

Saponins are also important therapeutically as they are shown to have hypolipidemic and anticancer activity. Saponins are also necessary for activity of cardiac glycosides. The two major types of steroidal sapogenin are diosgenin and hecogenin. Steroidal saponins are used in the commercial production of sex hormones for clinical use. For example, progesterone is derived from diosgenin. The most abundant starting material for the synthesis of progesterone is diosgenin isolated from Dioscorea species, formerly supplied from Mexico, and now from China [1]. Other steroidal hormones, e.g. cortisone and hydrocortisone, can be prepared from the starting material hecogenin, which can be isolated from Sisal leaves found extensively in East Africa [1].

Tannins: these are widely distributed in plant flora. They are phenolic compounds of high molecular weight. Tannins are soluble in water and alcohol and are found in the root, bark, stem and outer layers of plant tissue. Tannins have a characteristic feature to tan, i.e. to convert things into leather. They are acidic in reaction and the acidic reaction is attributed to the presence of phenolics or carboxylic group [15]. They form complexes with proteins, carbohydrates, gelatin and alkaloids. Tannins are divided into hydrolysable tannins and condensed tannins [15]. Hydrolysable tannins, upon hydrolysis, produce gallic acid and ellagic acid and depending on the type of acid produced, the hydrolysable tannins are called gallotannins or egallitannins. On heating, they form pyrogallic acid. Tannins are used as antiseptic and this activity is due to presence of the phenolic group. Common examples of hydrolysable tannins include theaflavins (from tea), daidezein, genistein and glycitein. Tannin rich medicinal plants are used as healing agents in a number of diseases. In Ayurveda, formulations based on tanninrich plants have been used for the treatment of diseases like leucorrhoea, rhinnorhoea and diarrhea [15]. G. Anthraquinones: these are derivatives of phenolic and glycosidic compounds. They are solely derived from anthracene giving variable oxidized derivatives such as anthrones and anthranols. Other derivatives such as chrysophanol, aloe-emodin, rhein, salinos poramide, luteolin and emodin have in common a double hydroxylation at positions $\mathrm{C}-1$ and $\mathrm{C}-8$. To test for free anthraquinones, powdered plant material is mixed with organic solvent and filtered, and an aqueous base, e.g. $\mathrm{NaOH}$ or $\mathrm{NH}_{4} \mathrm{OH}$ solution, is added to it. A pink or violet colour in the base layer indicates the presence of anthraquinones in the plant sample [1]. In their modes of action of phytochemicals behave as Antioxidants, Anticacinogens, Antimicrobials, Anti-ulcer, Antidiabetic, Anti-inflammatory.
Extraction and screening of phytochemicals: Extraction: (as the term is pharmaceutically used) is the separation of medicinally active portions of plant (and animal) tissues using selective solvents through standard procedures. The products so obtained from plants are relatively complex mixtures of metabolites, in liquid or semisolid state or (after removing the solvent) in dry powder form, and are intended for oral or external use. These include classes of preparations known as decoctions, infusions, fluid extracts, tinctures, pilular (semisolid) extracts or powdered extracts. Such preparations have been popularly called galenicals, named after Galen, the second century Greek physician [17].

Extraction methods used pharmaceutically involves the separation of medicinally active portions of plant tissues from the inactive/inert components by using selective solvents. During extraction, solvents diffuse into the solid plant material and solubilize compounds with similar polarity [17]. The purpose of standardized extraction procedures for crude drugs (medicinal plant parts) is to attain the therapeutically desired portions and to eliminate unwanted material by treatment with a selective solvent known as menstrum. The extract thus obtained, after standardization, may be used as medicinal agent as such in the form of tinctures or fluid extracts or further processed to be incorporated in any dosage form such as tablets and capsules. These products contain complex mixture of many medicinal plant metabolites, such as alkaloids, glycosides, terpenoids, flavonoids and lignans [18]. The general techniques of medicinal plant extraction include maceration, infusion, percolation, digestion, decoction, hot continuous extraction (Soxhlet), aqueous-alcoholic extraction by fermentation, countercurrent extraction, microwave-assisted extraction, ultrasound extraction (sonication), supercritical fluid extraction, and phytonic extraction (with hydro fluorocarbon solvents). For aromatic plants, hydrodistillation techniques (water distillation, steam distillation, water and steam distillation), hydrolytic maceration followed by distillation, expression and enfleurage (cold fat extraction) may be employed [17]. Some of the latest extraction methods for aromatic plants include headspace trapping, solid phase microextraction, protoplast extraction, microdistillation, thermomicro distillation and molecular distillation [17].

\section{RESEARCH METHOD}

The method adopted in this study involved the methanol extraction of Coconut Phytochemicals as developed by Trease and Evans [19]. The Spearman's Ranked Correlation Coefficient statistics technique was used to test the level of correlation between the visually scored colour intensity of the phytochemicals of interest and their spectrophotometric ally measured absorbance values at $200 \mathrm{~nm}$ to $600 \mathrm{~nm}$. The targeted Phytochemicals were Alkaloids, Glycosides, Saponins, Tannins, Resins, Acidic compounds and Flavonoids. 


\section{RESULTS}

Alkaloids that were subjectively scored 4+ with light Purple colour intensity had absorbance, OD, of 300nm. Tannins and Resins, scored 3+ each, with Light Blue colour intensity, had absorbance, OD, of 400nm. Glycosides and Saponin each separately scored

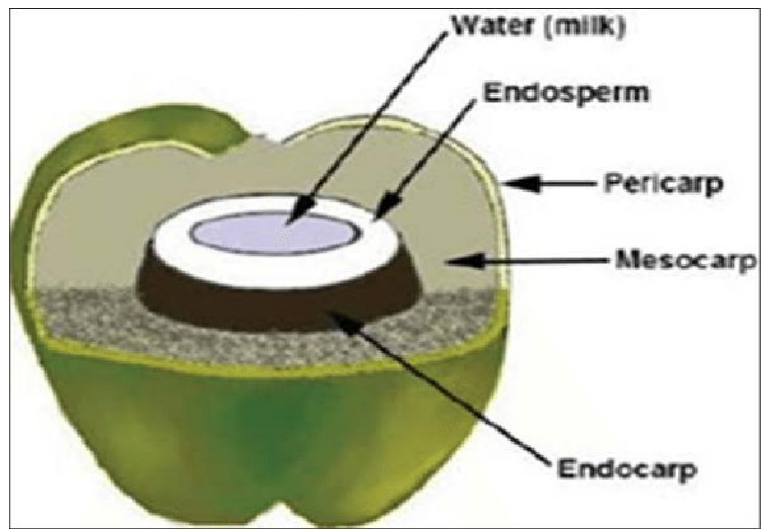

Fig-1: A Cross-sectional area of a coconut fruit
$2+$, with Green colour intensity had absorbance, OD, of $200 \mathrm{~nm}$. While no colors were detected in Flavonoids and Acidic compounds and as such their absorbances could not be evaluated. Their Statistical proportions on Pie Chart were $142.9^{0}, 102.9^{0}, 102.9^{0}$ and $0^{0}$ respectively.

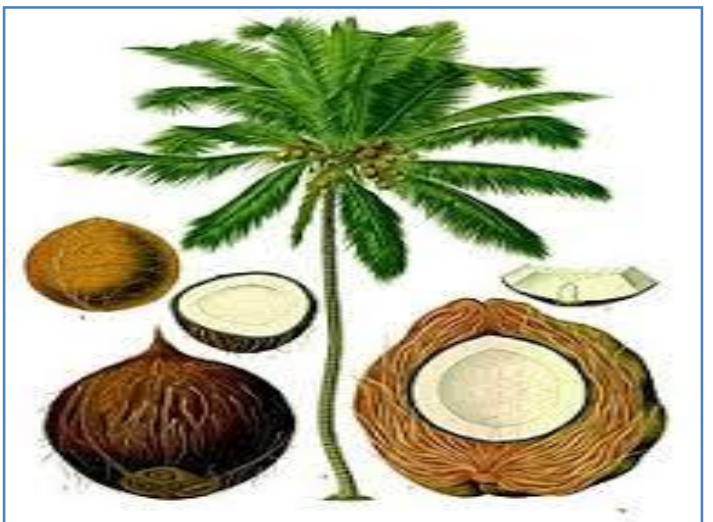

Fig-2: Coconut (Cocos nucifera) tree with fruits (b) A Crosssectional area of a coconut fruit

Table-1: Result of the phytochemical analysis of milled endosperm Cocos nucifera using polar solvent extract

(water)

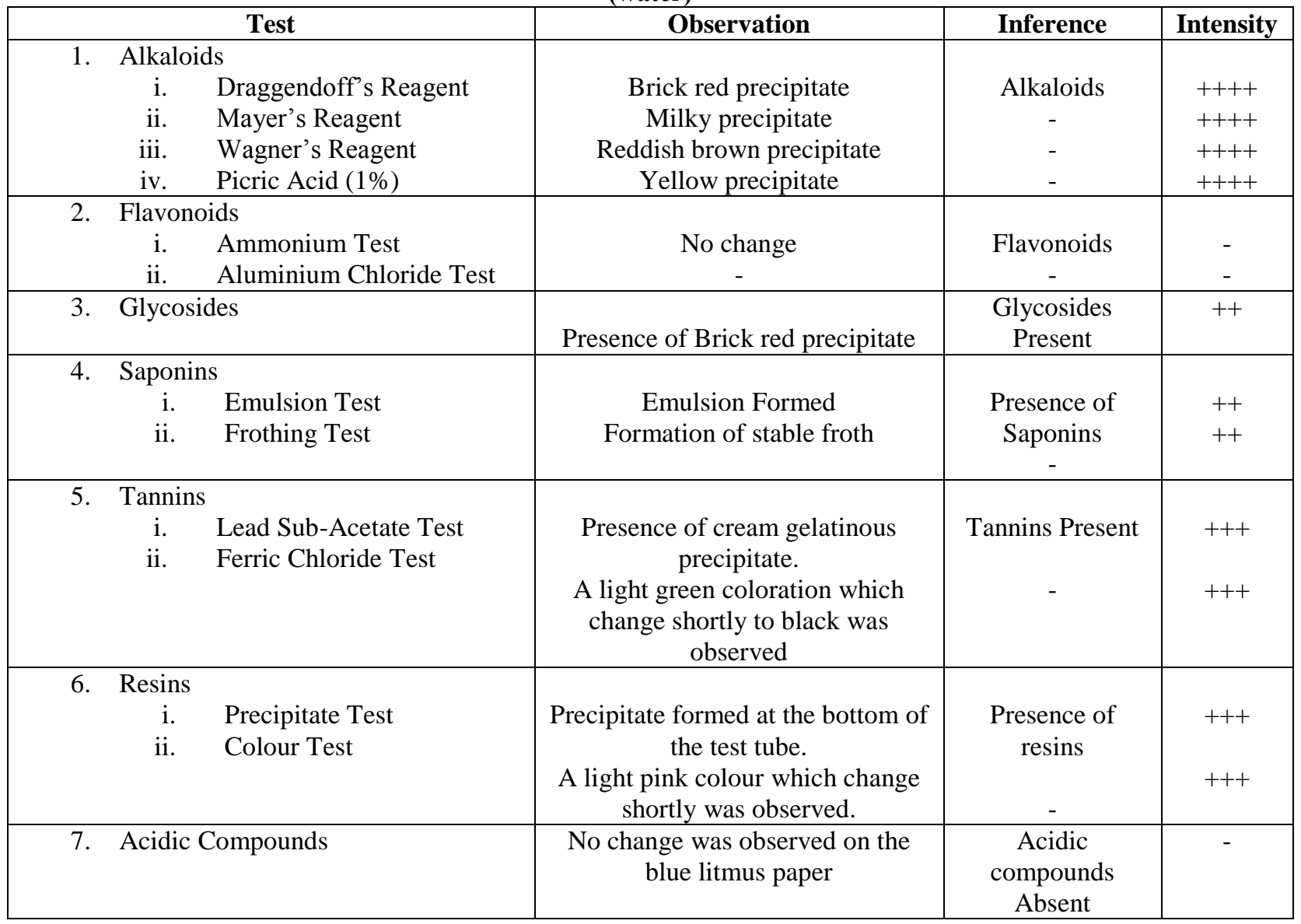


Table-2: Result of the phytochemical analysis of milled endosperm Cocos nucifera using a non-polar solvent extracts (n-hexane) and Methanol

\begin{tabular}{|c|c|c|c|c|c|c|}
\hline Test & Observation & Inference & Intensity & $\begin{array}{c}\text { Absorbance } \\
\text { Nm }\end{array}$ & $\begin{array}{c}\text { SDV } \pm \\
\text { Average } \\
\text { Absorbance } \\
\text { OD nm }\end{array}$ & $\begin{array}{c}\text { Proportion } \\
\text { Per } 360^{\circ}\end{array}$ \\
\hline \begin{tabular}{|l} 
8. Alkaloids \\
v. Draggendoff's \\
Reagent \\
vi.Mayer's Reagent \\
vii. Wagner's Reagent \\
viii.Picric Acid (1\%)
\end{tabular} & $\begin{array}{c}\text { Brick red } \\
\text { precipitate } \\
\text { Milky precipitate } \\
\text { Reddish brown } \\
\text { precipitate } \\
\text { Yellow precipitate }\end{array}$ & $\begin{array}{c}\text { Alkaloids } \\
- \\
- \\
-\end{array}$ & $\begin{array}{l}++++ \\
++++ \\
++++ \\
++++\end{array}$ & $\begin{array}{l}405 \\
402 \\
398 \\
395\end{array}$ & $4.4 \pm 400$ & $102.90^{0}$ \\
\hline $\begin{array}{l}\text { 9. Flavonoids } \\
\text { iii.Ammonium Test } \\
\text { iv.Aluminium Chloride } \\
\text { Test }\end{array}$ & $\begin{array}{c}\text { No change } \\
-\end{array}$ & $\begin{array}{c}\text { Flavonoids } \\
-\end{array}$ & $\begin{array}{l}- \\
-\end{array}$ & $\begin{array}{l}0 \\
0\end{array}$ & 0 & 0 \\
\hline 10. Glycosides & $\begin{array}{l}\text { Presence of Brick } \\
\text { red precipitate }\end{array}$ & $\begin{array}{l}\text { Glycosides } \\
\text { Present }\end{array}$ & ++ & 200 & 200 & $51.43^{0}$ \\
\hline $\begin{array}{l}\text { 11. Saponins } \\
\text { iii.Emulsion Test } \\
\text { iv.Frothing Test }\end{array}$ & $\begin{array}{l}\text { Emulsion Formed } \\
\text { Formation of } \\
\text { stable froth }\end{array}$ & $\begin{array}{c}\text { Presence of } \\
\text { Saponins } \\
-\end{array}$ & $\begin{array}{l}++ \\
++\end{array}$ & $\begin{array}{l}220 \\
180\end{array}$ & $20 \pm 200$ & $51.43^{0}$ \\
\hline $\begin{array}{l}\text { 12. Tannins } \\
\text { iii.Lead Sub-acetate } \\
\text { Test } \\
\text { iv.Ferric Chloride Test }\end{array}$ & $\begin{array}{c}\text { Presence of cream } \\
\text { gelatinous } \\
\text { precipitate. } \\
\text { A light green } \\
\text { coloration which } \\
\text { change shortly to } \\
\text { black was } \\
\text { observed }\end{array}$ & $\begin{array}{c}\text { Tannins } \\
\text { Present } \\
-\end{array}$ & $\begin{array}{l}+++ \\
+++\end{array}$ & $\begin{array}{l}295 \\
305\end{array}$ & $5 \pm 300$ & $77.14^{0}$ \\
\hline $\begin{array}{l}\text { 13. Resins } \\
\text { iii.Precipitate Test } \\
\text { iv.Colour Test }\end{array}$ & $\begin{array}{l}\text { Precipitate formed } \\
\text { at the bottom of } \\
\text { the test tube. } \\
\text { A light pink } \\
\text { colour which } \\
\text { change shortly } \\
\text { was observed. }\end{array}$ & $\begin{array}{l}\text { Presence of } \\
\text { resins } \\
-\end{array}$ & $\begin{array}{l}+++ \\
+++\end{array}$ & $\begin{array}{l}280 \\
320\end{array}$ & $20 \pm 300$ & $77.14^{0}$ \\
\hline $\begin{array}{l}\text { 14. Acidic } \\
\text { Compounds }\end{array}$ & $\begin{array}{l}\text { No change was } \\
\text { observed on the } \\
\text { blue litmus paper }\end{array}$ & $\begin{array}{c}\text { Acidic } \\
\text { compounds } \\
\text { Absent } \\
\end{array}$ & - & 0 & 0 & 0 \\
\hline
\end{tabular}

SDV $=$ STANDARD DEVIATION

Table-3: Relating phytochemicals proportions with absorbances and colour codes

\begin{tabular}{|c|c|c|c|c|c|}
\hline PHYTOCHEMICALS & $\begin{array}{c}\text { ABSORBANCE } \\
\text { OD }(\mathbf{n m})\end{array}$ & PROPORTION/360 ${ }^{\circ}$ & COMBINED & QUADRANT & $\begin{array}{l}\text { COLOUR } \\
\text { CODE }\end{array}$ \\
\hline ALKALOIDS & 400 & 102.90 & 102.9 & $2^{\text {nd }}$ & $\begin{array}{c}\text { LIGHT } \\
\text { PURPLE }\end{array}$ \\
\hline GLYCOSIDES & 200 & 51.43 & \multirow{2}{*}{102.9} & \multirow{2}{*}{$3^{\mathrm{RD}}$} & GREEN \\
\hline SAPONIN & 200 & 51.43 & & & GREEN \\
\hline TANIN & 300 & 71.14 & \multirow{2}{*}{142.28} & \multirow{2}{*}{$1^{\text {st }}$} & $\begin{array}{l}\text { LIGHT } \\
\text { BLUE }\end{array}$ \\
\hline RESINS & 300 & 71.14 & & & $\begin{array}{l}\text { LIGHT } \\
\text { BLUE }\end{array}$ \\
\hline $\begin{array}{c}\text { ACIDIC } \\
\text { COMPOUNDS }\end{array}$ & 0 & 0 & \multirow[t]{2}{*}{0} & NIL & NIL \\
\hline FLAVONOIDS & 0 & 0 & & NIL & NIL \\
\hline
\end{tabular}




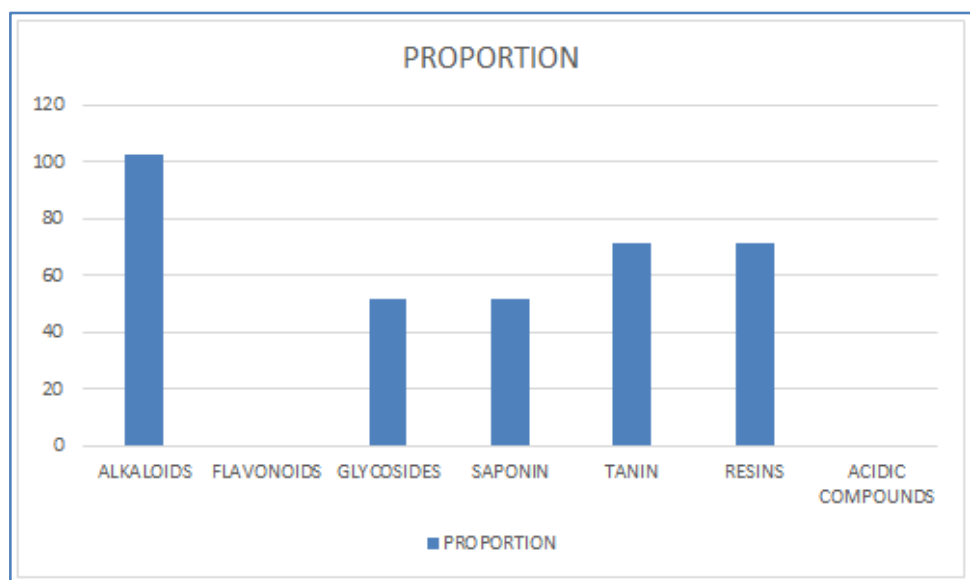

Fig-3: Bar chart showing the proportion of the phytochemicals

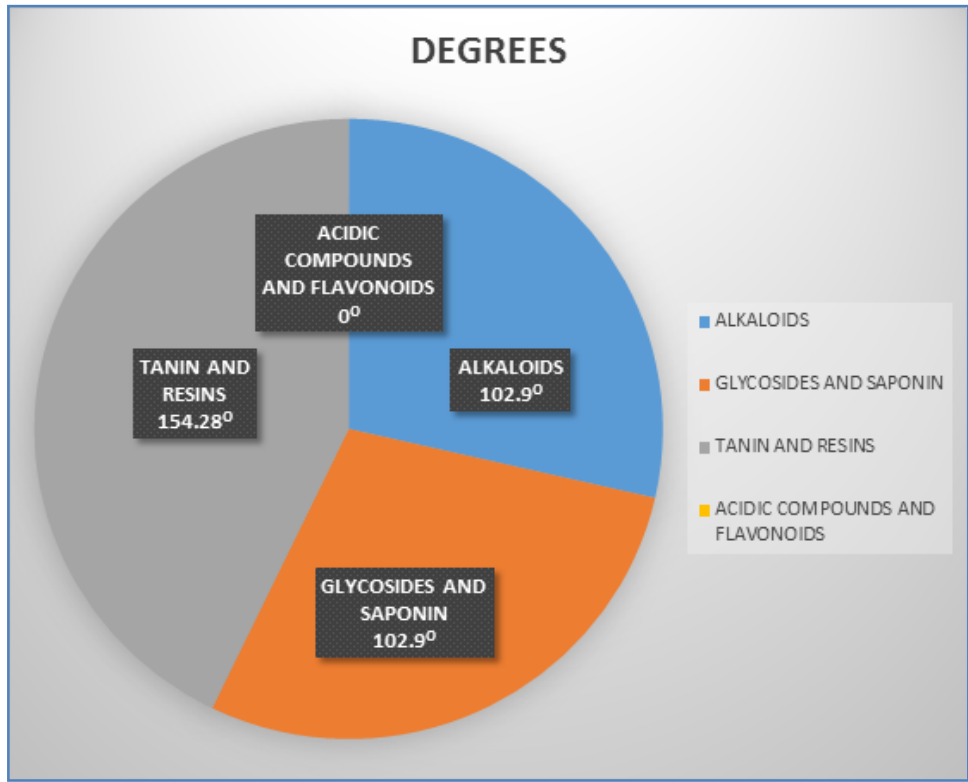

Fig-4: Pie chart to illustrate the Phytochemical Analysis intensity of milled endosperm Cocos nucifera using non-polar solvent (Methanolic acid)

\section{DISCUSSION}

The phytochemical analyses on the endosperm of Cocos nucifera $L$ showed the presence of alkaloids, tannins and resins and in high concentration as indicated by the intensity of the colored solution and precipitates formed on detection. Saponins and glycosides were present in moderate concentration. Terpenoids and steroids had the least concentration. The macronutrient analyses showed the presence of carbohydrate, fats and oils in high concentration while reducing sugar and proteins were present in moderate concentration. Each result of these analyses (phytochemical and macronutrient), presented in two parts showed the analyses using aqueous and n-hexane /Methanol extracts.

Some phytochemicals were present in smaller concentration in one of the extract while being present in higher concentration in the other extract. This can be attributed to their volatility as they may have evaporated during the concentration of $n$-hexane extract while heating in a water bath. Some macronutrients were also detected. From this research, the presence of phenolic compounds such as terpenoids, steroids (phytosterols i.e. $\beta$-sitosterol) though in very low concentration contributes to the antioxidant properties of coconut. It is known that coconut is a poor source of phytosterol. The phytosterols fight atherosclerosis and reduce the growth of cancer cells. For many years now, it has been known that plant polyphenols (steroids, terpenoids, flavonoids e.t.c) are antioxidants in vitro. These antioxidants are compounds that reduce the formation of free radicals or react with and neutralize them thus potentially protecting the cell from oxidative damage. The tannins and resins are employed as astringent both in gastro-intestinal tract and on skin abrasions. On the other hand, the macronutrients; proteins, carbohydrate and reducing sugar are involved in the energy giving and bodybuilding function of coconut. The fats and oil constituent of coconut has many functions as the different types of fatty acids contained; all have different functions to perform. Coconut oil contains about $50 \%$ lauric acid. The lauric 
acid is a medium chain fatty, which is abundant in coconut oil, and considered responsible for many of its health benefits. The lauric acid has the additional beneficial function of being converted into monolaurin in the human body. Monolaurin is the antifungal, antibacterial, antiprotozoal and antiviral monoglyceride formed from the metabolism of lauric acid.

\section{Conclusions}

The results obtained from the phytochemical analyses of the endosperm of cocos nucifera 1 showed the presence of alkaloids, resins, steroids, terpenoids, and the absence of flavonoids and acidic compounds while the macronutrient analyses revealed the presence of proteins, carbohydrate, reducing sugar, fats and oil. This study justifies the use of cocos nucifera 1 in the treatment of many debilitating ailments like cancer, diabetes, ulcer, obesity, heart disease and infections due to micro-organisms. However, the medicinal/pharmacological usage of cocos nucifera is as a result of the oil present in it and its non-nutrient (phytochemical) content which act as antioxidants against dangerous free radicals in the body system.

\section{REFERENCES}

1. Sarker SD, Nahar L. Chemistry for pharmacy students. John Willey \& Sons Ltd. UK. 2007:3224.

2. Doughari JH, Human IS, Benadé AJ, Ndakidemi PA. Phytochemicals as chemotherapeutic agents and antioxidants: Possible solution to the control of antibiotic resistant verocytotoxin producing bacteria. 2009.

3. Nweze EI, Okafor JI, Njoku O. Antimicrobial activities of methanolic extracts of Trema guineensis (Schumm and Thorn) and Morinda lucida benth used in Nigerian. Bio-research. 2004 Jul 16;2(1):39-46.

4. Doughari JH, Obidah JS. Antibacterial potentials of stem bark extracts of Leptadenia lancifolia against some pathogenic bacteria. Pharmacologyonline. 2008 Jun;3:172-80.

5. Heinrich M, Barnes J, Gibbons S and Williamson EM. Fundamental of Pharmacognosy and Phytotherapy. Churchill living stone, Edinburgh. 2004: 245-252.

6. El-Ghazali GE, Al-Khalifa KS, Saleem GA, Abdallah EM. Traditional medicinal plants indigenous to Al-Rass province, Saudi Arabia.
Journal of Medicinal Plants Research. 2010 Dec 18;4(24):2680-3.

7. Cousins D, Huffman MA. Medicinal properties in the diet of gorillas: an ethno-pharmacological evaluation.

8. Adekunle AS, Adekunle OC. Preliminary assessment of antimicrobial properties of aqueous extract of plants against infectious diseases. Biology and Medicine. 2009;1(3):20-4.

9. Obi V. I and Onuoha, C. Extraction and Characterization Methods of Plants and Plant Production in Biological and Agricultural Techniques, Ogbulie, JN and Ojiako, O. J.

10. Voravuthikunchai SP. Activities of crude extracts of Thai medicinal plants on methicillin-resistant Staphylococcus aureus. J. Clin. Microbiol. Infect.. 2003;9:236

11. Rios JL, Recio MC. Medicinal plants and antimicrobial activity. Journal of ethnopharmacology. 2005 Aug 22;100(1-2):80-4.

12. Firn R. Nature's Chemicals Oxford University Press, Oxford.2010:74-75.

13. Madziga HA, Sanni S, Sandabe UK. Phytochemical and elemental analysis of Acalypha wilkesiana leaf. Journal of American Science. 2010;6(11):510-4.

14. Rojas V, Gil JV, Piñaga F, Manzanares P. Studies on acetate ester production by non-Saccharomyces wine yeasts. International journal of food microbiology. 2001 Nov 8;70(3):283-9.

15. Kar A. Pharmacognosy and Pharmacobiotechnology (Revised- Expanded Second Edition). New Age New Delhi. 2007: 332 600.

16. Puupponen-Pimiä R, Nohynek L, Ammann S, Oksman-Caldentey KM, Buchert J. Enzymeassisted processing increases antimicrobial and antioxidant activity of bilberry. Journal of Agricultural and Food Chemistry. 2008 Feb 13;56(3):681-8.

17. Awad AB, Bradford PG, editors. Nutrition and Cancer Prevention. CRC Press; 2005 Sep 19.

18. Aggarwal BB, Shishodia S. Molecular targets of dietary agents for prevention and therapy of cancer. Biochemical pharmacology. 2006 May 14;71(10):1397-421.

19. Trease GE, Evans WC. Textbook of Pharmacognosy. $12^{\text {th }}$ edn. Balliese Tindall and Company Publisher, London. 1983: 343-383. 